\title{
A study to derive a clinical decision rule for triage of emergency department patients with chest pain: design and methodology Erik P Hess*1, George A Wells ${ }^{2}$, Allan Jaffe ${ }^{3}$ and Ian G Stiell ${ }^{4}$
}

Address: ${ }^{1}$ Department of Emergency Medicine, University of Ottawa, Ottawa, Canada, ${ }^{2}$ Department of Epidemiology and Community Medicine, University of Ottawa, Ottawa, Canada, ${ }^{3}$ Department of Internal Medicine, Division of Cardiology, Mayo Clinic College of Medicine, Rochester, USA and ${ }^{4}$ Department of Emergency Medicine, Department of Epidemiology and Community Medicine, University of Ottawa, Ottawa, Canada

Email: Erik P Hess* - hess.erik@mayo.edu; George A Wells - gawells@ottawaheart.ca; Allan Jaffe - jaffe.allan@mayo.edu; Ian G Stiell - istiell@ohri.ca

* Corresponding author

Published: 6 February 2008

BMC Emergency Medicine 2008, 8:3 doi:10.1 186/147/-227X-8-3

This article is available from: http://www.biomedcentral.com/I47I-227X/8/3

This is an Open Access article distributed under the terms of the Creative Commons Attribution License (http://creativecommons.org/licenses/by/2.0), which permits unrestricted use, distribution, and reproduction in any medium, provided the original work is properly cited.

\begin{abstract}
Background: Chest pain is the second most common chief complaint in North American emergency departments. Data from the U.S. suggest that $2.1 \%$ of patients with acute myocardial infarction and $2.3 \%$ of patients with unstable angina are misdiagnosed, with slightly higher rates reported in a recent Canadian study ( $4.6 \%$ and $6.4 \%$, respectively). Information obtained from the history, 12-lead ECG, and a single set of cardiac enzymes is unable to identify patients who are safe for early discharge with sufficient sensitivity. The 2007 ACC/AHA guidelines for UA/NSTEMI do not identify patients at low risk for adverse cardiac events who can be safely discharged without provocative testing. As a result large numbers of low risk patients are triaged to chest pain observation units and undergo provocative testing, at significant cost to the healthcare system. Clinical decision rules use clinical findings (history, physical exam, test results) to suggest a diagnostic or therapeutic course of action. Currently no methodologically robust clinical decision rule identifies patients safe for early discharge.
\end{abstract}

Methods/design: The goal of this study is to derive a clinical decision rule which will allow emergency physicians to accurately identify patients with chest pain who are safe for early discharge. The study will utilize a prospective cohort design. Standardized clinical variables will be collected on all patients at least 25 years of age complaining of chest pain prior to provocative testing. Variables strongly associated with the composite outcome acute myocardial infarction, revascularization, or death will be further analyzed with multivariable analysis to derive the clinical rule. Specific aims are to: i) apply standardized clinical assessments to patients with chest pain, incorporating results of early cardiac testing; ii) determine the inter-observer reliability of the clinical information; iii) determine the statistical association between the clinical findings and the composite outcome; and iv) use multivariable analysis to derive a highly sensitive clinical decision rule to guide triage decisions.

Discussion: The study will derive a highly sensitive clinical decision rule to identify low risk patients safe for early discharge. This will improve patient care, lower healthcare costs, and enhance flow in our busy and overcrowded emergency departments. 


\section{Background}

Patients with acute chest pain often undergo extensive diagnostic testing and risk stratification to diagnose acute coronary syndrome (ACS) and determine the likelihood of future adverse cardiac events. Chest pain can be either cardiac or noncardiac in etiology and represents a continuum of risk from benign self-limiting conditions to lifethreatening illness requiring rapid diagnosis and treatment. Currently it is not well established which patients require extensive diagnostic investigation. The goal of this study is to derive a clinical decision rule that predicts adverse cardiac events with a high degree of sensitivity and which will allow emergency physicians to accurately identify patients with chest pain who are safe for early discharge without provocative testing.

Definition and epidemiology of acute coronary syndromes ACS is a term that encompasses the disease entities unstable angina pectoris, non-ST-segment elevation myocardial infarction (NSTEMI), and ST-segment elevation myocardial infarction (STEMI). Although myocardial infarction has been defined by a number of clinical, electrocardiographic (ECG), and biochemical characteristics, it is generally agreed that the term indicates death of cardiac myocytes due to prolonged ischemia [1]. Unstable angina pectoris, on the other hand, indicates myocardial ischemia without biochemical evidence of cardiac myocyte death [2].

Data from the 2004 National Hospital Ambulatory Medical Care Survey indicate that chest pain is the second most common chief complaint in North American emergency departments, accounting for 6 million patient visits [3]. Approximately 565,000 patients are ultimately diagnosed with acute myocardial infarction, and nearly twice as many are diagnosed with unstable angina pectoris [4-6].

\section{Statement of the problem in the emergency department}

Chest pain is a diagnostic dilemma for the emergency physician. Data from a recent Canadian study suggest that $4.6 \%$ of patients with acute myocardial infarction and $6.4 \%$ of patients with unstable angina are misdiagnosed in the emergency department [7], with slightly lower rates reported in the U.S. (2.1\% and 2.3\%, respectively) [8]. In patients without a prior cardiac history, the challenge is to determine if the chest pain is cardiac in etiology. In patients with a prior cardiac history, the challenge is to determine the short-term risk of adverse outcome.

Information obtained from the history, initial 12-lead ECG, and a single set of cardiac enzymes to detect myocardial necrosis is unable to identify patients who are safe for early discharge with sufficient sensitivity $[9,10]$. Neither the 2007 ACC/AHA guidelines for the management of patients with unstable angina and NSTEMI nor the practi- cal implementation of the 2002 AHA guidelines for the emergency department proposed by Gibler et. al identify a group of patients at very low risk for adverse cardiac events who can be safely discharged without provocative testing $[11,12]$. In the absence of guidelines that accurately and reliably identify patients safe for early discharge, physicians' triage decisions are variable and often influenced by level of perceived medical and legal risk [13-15]. As a result patients at very low risk for adverse outcome are often triaged to chest pain observation units and undergo extensive risk stratification protocols based on an unstructured assessment of pretest probability and perceived legal risk [16]. High sensitivity is ensured at the expense of specificity, with increased likelihood of false positive provocative testing and significant cost to the healthcare system.

\section{Methodologic standards for clinical decision rules}

Concomitant with the reporting of various decision rules has been an interest in the methodological standards for their development and validation $[17,18]$. These standards may be summarized as follows: 1) The outcome or diagnosis to be predicted must be clearly defined and the assessment of this outcome should be made in a blinded fashion. 2) The clinical findings to be used as predictors must be clearly defined and standardized and their assessment must be done without knowledge of the outcome. 3) The reliability or reproducibility of the clinical findings used as predictors must be demonstrated. 4) The subjects in the study should be selected without bias and should represent a wide spectrum of clinical and demographic characteristics to increase the generalizability of the results. 5) The mathematical techniques for deriving the rule must be identified. 6) Clinical decision rules should be sensible: have a clear purpose, be relevant, demonstrate content validity, be concise, and be easy to use in the intended clinical application. 7) The accuracy of the decision rule in classifying patients with (sensitivity) and without (specificity) the targeted outcome should be demonstrated. 8) Prospective validation on a new set of patients is an essential test of accuracy because misclassification is commonly higher when decision rules are tested on a population other than the original derivation set. 9) Implementation to demonstrate the true effect on patient care is the ultimate test of a decision rule; transportability can be tested at this stage.

\section{Review of previous studies}

Currently, there is no decision rule that is widely used in Canadian and U.S. emergency departments. Although a number of studies have been published that risk stratify patients who present to the emergency department with chest pain, none that directly address the clinical question at hand could be considered methodologically robust according to the criteria described previously [19]. Some 
of the methodologic deficiencies will be described in the following paragraphs.

The specific outcome measures varied considerably among the studies, consisting of acute myocardial infarction alone [20-32], acute myocardial infarction and unstable angina [33-37], acute myocardial infarction and death [38-40], all-cause mortality, acute myocardial infarction, and need for revascularization [10,41-50], and similar composite outcomes with slight variations [19,51-63]. Most studies did not report assessing the outcome without knowledge of the predictor variables.

Fourteen studies reported assessing the predictor variables in a standardized fashion with a data collection sheet specifically designed for a prediction rule study $[19,22,23,25,26,31,33,34,47,50,56-59]$. However, only four explicitly reported collecting the predictor variables without knowledge of the outcome $[19,50,56,57]$.

Only one study assessed the reliability of the clinical findings to be used as predictors in the rule [19]. However, this study did not report kappa values for the predictor variables considered for inclusion in the rule.

The definition of subjects in previous studies has been extremely variable making it difficult for physicians to interpret and apply the findings to their own patients. Several studies did not specify age criteria for enrolment [23,27-31,33,35,39-41,44,45,48-50,52,55,56,58,60].

Among those that did specify age criteria, different criteria were used: over the age of $18[21,22,34,38,54,59,63]$, over the age of $20[43,46]$, over the age of $24[10,24,47]$, over the age of $25[19,25,26,53]$, over the age of 30 [32,36,42,51,61], between 20 and 80 years of age [62], and between 24 and 39 years of age $[57,64]$. In some studies all patients with a primary complaint of chest pain were eligible for enrolment [19,21,22,24-29,31$34,43,44,46,49,53,54]$, whereas others required additional or different eligibility criteria [10,23,24,30,35,36,38-42,45,47,48,50-52,54-63,65].

Exclusion criteria varied greatly among the studies as well.

The mathematical techniques were described in all of the studies except one [31]. Several studies developed prediction rules that lacked clinical sensibility and were not easily used in the intended clinical application [21$31,33,34,36,50,52,59,61,62]$. Twenty-four studies reported the accuracy of the decision rule in terms of sensitivity and specificity in diagnosing the predicted outcome $[10,19,21-30,32-35,45,49,50,54,59,60,62,65]$.

Twelve prediction rules have been prospectively validated on a different set of patients from which the rule was derived $[21,22,25,26,34,37,42,53,55,57,61,65]$. None of these have consistently performed with sensitivities of $\geq$ $98 \%$ across studies [66]. Only three prediction rules have been implemented to demonstrate their true effect on patient care $[25,36,56]$. The clinical decision rule developed by Goldman et al. [25] had a sensitivity of $88 \%$ documented in the implementation phase, and the outcome was limited to acute myocardial infarction. Sensitivities as low as $62 \%$ have been reported for the decision rule by Selker et al. [36]. Finally, the decision rule developed by Reilly et al. [56] addressed the decision of whether to admit emergency department patients with chest pain to the hospital ward or intensive care unit, not whether to discharge a patient home or arrange additional observation and diagnostic testing.

\section{Objectives}

The goal is to derive a clinical decision rule that is highly sensitive for predicting adverse cardiac events and which will allow emergency department physicians to accurately identify patients with chest pain who are safe for early discharge without prolonged emergency department observation, hospital admission, or provocative testing. Specific objectives are: 1) To develop and pretest standardized clinical assessment methods for patients with acute chest pain, incorporating results of initial cardiac testing. 2) To apply these standardized clinical assessments to patients with chest pain. 3) To determine the interobserver reliability of the clinical findings. 4) To determine the association between the clinical findings and the development of adverse cardiac events within 30 days. 5) To use multivariate techniques to derive a highly sensitive clinical decision rule for patients with chest pain to guide triage decisions and selection of further diagnostic testing. 6) To assess the classification performance of the derived decision rule. 7) To determine emergency physicians' accuracy in predicting acute coronary syndrome without the decision rule.

\section{Methods/design}

\section{Study design and setting}

This will be a prospective cohort study in which consecutive emergency department patients with a chief complaint of chest pain and possible ACS will be enrolled. The study will be conducted a tertiary care academic emergency department in Ottawa, Ontario, Canada with an annual census of approximately 60,000 patient visits.

\section{Study population}

All adult patients at least 25 years of age with a primary complaint of chest pain of at least 5 minutes duration and possible ACS will be eligible for enrolment. Patient eligibility will be determined by the attending emergency physician on duty based on clinical judgment. 
Patients will be excluded if any of the following criteria are met: 1) Acute ST-segment elevation $(\geq 0.1 \mathrm{mV}$ in limb leads or $\geq 0.2 \mathrm{mV}$ in precordial leads) on the initial ECG. 2) Hemodynamic instability or tachycardia (systolic blood pressure $<90 \mathrm{mmHg}$, bradycardia $<50$ beats/min, tachycardia $>100$ beats/min). 3) Pulmonary edema on chest x-ray. 4) Age $<25$ years. 5) A history of cocaine use or positive test for cocaine. 6) Severe communication problems such that a reliable history cannot be obtained. 7) A clear traumatic etiology of the chest pain. 8) A radiologically-evident cause of chest pain on chest x-ray (e.g., pneumonia, pneumothorax). 9) Prior enrolment in the study within the past 30 days. 10) Terminal non-cardiac illness. 11) No available phone contact. 12) Pregnancy.

\section{Patient assessment}

All patient assessments will be made by staff physicians who are certified in emergency medicine by the Royal College of Physicians and Surgeons in Canada and/or the College of Family Physicians of Canada. Rotating housestaff will perform patient assessments per standard practice but will be asked to have the staff physicians perform study assessments. The primary investigator will orient each of the physician assessors individually and provide one-on-one training to ensure uniform data collection. All physicians will complete data collection forms after assessing the patient and before obtaining results of diagnostic tests, without knowledge of the outcome.

\section{Quality assurance}

Throughout the duration of the study, the completeness of data collection and compliance in patient enrolment will be monitored. Physicians will be given regular feedback regarding their completeness of data collection. No feedback regarding the reliability or accuracy of each of the predictor variables will be given.

\section{Selection of variables}

The variables selected for assessment in the study were chosen based on review of the literature, input from all the investigators, and solicited feedback from the designator physicians. The number of variables collected was limited to ensure efficient completion of data forms in the context of patient care and optimize physician compliance. The variables to be collected on each patient are listed in Tables 1 and 2.

\section{Electrocardiogram interpretation and cardiac biomarker assessment}

Investigators blinded to the final outcome will review all ECG's in a structured format to identify the presence or absence of ST segment elevation or depression (classified as $<0.05 \mathrm{mV}, 0.05$ to $0.1 \mathrm{mV}$, and $>1.0 \mathrm{mV}$ deviation) in at least 2 contiguous leads, T-wave inversion $(\geq 0.2 \mathrm{mV}$ when isolated or $<0.2 \mathrm{mV}$ when in 2 or more contiguous leads with dominant $\mathrm{R}$ waves), left bundle branch block, right bundle branch block, or pathological Q-waves. Each of these findings will be categorized as "known to be old"

Table I: List of prospectively collected historical variables.

\begin{tabular}{|c|c|c|}
\hline Demographics & $\begin{array}{l}\text { - Age (years) } \\
\text { - Date of emergency visit (d/m/y) }\end{array}$ & $\begin{array}{l}\text { - Gender (male/female) } \\
\text { - Arrival by ambulance }\end{array}$ \\
\hline Cardiac medications & $\begin{array}{l}\text { - Aspirin } \\
\text { - Clopidogrel } \\
\text { - Other anticoagulants (warfarin, aspirin/dipyridamole) } \\
\text { - Beta blockers } \\
\text { - Calcium channel blockers }\end{array}$ & $\begin{array}{l}\text { - Nitroglycerin (or other nitrates) } \\
\text { - Angiotensin converting enzyme inhibitors } \\
\text { - Cholesterol-lowering drugs }\end{array}$ \\
\hline Cardiac risk factors & $\begin{array}{l}\text { - Hypertension } \\
\text { - Diabetes Mellitus } \\
\text { - Hypercholesterolemia } \\
\text { - Renal insufficiency }\end{array}$ & $\begin{array}{l}\text { - Family history of cardiac disease } \\
\text { - Smoking history }\end{array}$ \\
\hline Cardiac history & $\begin{array}{l}\text { - Acute myocardial infarction } \\
\text { - Cardiac arrest } \\
\text { - Peripheral vascular disease } \\
\text { - Angina } \\
\text { - Ventricular tachycardia }\end{array}$ & $\begin{array}{l}\text { - Known coronary artery disease } \\
\text { - Atrial fibrillation } \\
\text { - Congestive heart failure } \\
\text { - Stroke or transient ischemic attack }\end{array}$ \\
\hline Chest pain characteristics & $\begin{array}{l}\text { - Duration and time of onset of longest episode (days, } \\
\text { hours, minutes; a.m., p.m.) } \\
\text { - Was the pain present on arrival to the ED? } \\
\text { - Is the pain worse with exertion? } \\
\text { - Is the pain similar to previously diagnosed ischemia? } \\
\text { - Has there been } 2 \text { or more episodes of pain in the last } \\
24 \text { hours? } \\
\text { - Where on the chest is the pain located? } \\
\text { - Does the pain radiate? } \\
\text { - Is the pain worse with movement or position? } \\
\text { - The physician's overall assessment of the pain (typical } \\
\text { or atypical) }\end{array}$ & $\begin{array}{l}\text { - Has the pain completely resolved? } \\
\text { - Is the pain present at rest? } \\
\text { - Is the pain pleuritic (sharp, worse with deep } \\
\text { breathing)? } \\
\text { - Has there been a change in the usual pattern of angina } \\
\text { within the last } 24 \text { hours? } \\
\text { - Did the pain recur during the ED visit? } \\
\text { - How would you describe the pain? } \\
\text { - Is the pain associated with nausea, vomiting, or } \\
\text { diaphoresis? }\end{array}$ \\
\hline
\end{tabular}


Table 2: List of variables to be prospectively collected from the physical examination and diagnostic tests.

\begin{tabular}{|c|c|c|}
\hline & Variables to be Collected & \\
\hline Physical Examination & $\begin{array}{l}\text { - Temperature (degrees Celsius) } \\
\text { - Heart rate (beats per minute) } \\
\text { - Systolic blood pressure (mm of } \mathrm{Hg} \text { ) } \\
\text { - Diastolic blood pressure (mm of } \mathrm{Hg} \text { ) } \\
\text { - Cardiac auscultation findings (S3, S4, Systolic murmur, diastolic murmur) }\end{array}$ & $\begin{array}{l}\text { - Lung auscultation findings (crackles/ } \\
\text { rales at bases, crackles/rales to scapulae, } \\
\text { wheezes) } \\
\text { - Chest wall tenderness (reproducing } \\
\text { presenting symptom) } \\
\text { - Pitting edema in lower extremities }\end{array}$ \\
\hline Diagnostic tests & $\begin{array}{l}\text { - Intepretation of first readable ECG (normal, nonspecific ST-T wave } \\
\text { changes, abnormal but not diagnostic of ischemia, infarction or ischemia } \\
\text { known to be old, infarction or ischemia not known to be old, consistent } \\
\text { with AMI (ST-elevation or new left bundle branch block) } \\
\text { - Cardiac stress test done } \\
\text { - If yes, type of stress test (nuclear, exercise, stress echo, other) } \\
\text { - If yes, result (positive for ischemia, negative for ischemia, equivocal) } \\
\text { - If equivocal, mild ischemia, moderate ischemia, or severe ischemia? }\end{array}$ & $\begin{array}{l}\text { - Time and values of first and second } \\
\text { cardiac troponin T } \\
\text { - Cardiac CT done? } \\
\text { - If yes, any stenosis } \geq 70 \% \text { ? } \\
\text { - Coronary angiography done? } \\
\text { - If yes, any stenosis } \geq 70 \% \text { ? } \\
\text { - Did the patient undergo } \\
\text { revascularization? } \\
\text { - If yes, stent placement, angioplasty } \\
\text { alone, or coronary artery bypass grafting? }\end{array}$ \\
\hline Physician judgment & $\begin{array}{l}\text { - Probability of unstable angina or acute myocardial infarction (to the closest } \\
\text { percent) }\end{array}$ & \\
\hline
\end{tabular}

or "not known to be old." The overall interpretation of the ECG will be categorized as normal, nonspecific ST-T wave changes, abnormal but not diagnostic of ischemia, infarction or ischemia known to be old, infarction or ischemia not known to be old, or consistent with acute myocardial infarction (ST-segment elevation or new left bundlebranch block). This ECG classification system is known to have high inter-rater reliability and to correlate well with 30 -day outcome rates of death, myocardial infarction, and revascularization $[67,68]$.

Cardiac troponin T (cTNT) has been reported to have a higher sensitivity than CK-MB for diagnosis of acute myocardial infarction [69], and current guidelines suggest using CTNT as the sole cardiac marker to detect cardiac ischemia [70]. Thus, the sole cardiac marker utilized in this study will be cardiac cTnT (Elecsys Troponin T, Roche Diagnostics, Indianapolis, Indiana). The $99^{\text {th }}$ percentile of the reference range is $<0.01 \mu \mathrm{g} / \mathrm{L}$. The lowest concentration at which $10 \%$ imprecision is achieved $(10 \%$ coefficient of variation) is $0.035 \mu \mathrm{g} / \mathrm{L}$. Some have suggested using the $10 \%$ coefficient of variation as the cutoff for myocardial injury to increase specificity and exclude other causes of cTNT elevation such as chronic kidney disease, left ventricular hypertrophy, pulmonary embolism, or sepsis $[71,72]$. However, several studies have shown that any detectable elevation in cTNT identifies patients at high risk for ischemic complications, and a rising or falling pattern of cTNT can distinguish acute from chronic disease [73-76]. In a robust emergency department trial by Hamm et al. almost every patient at short term risk (30 days) was identified by elevations in CTNT above the $99^{\text {th }}$ percentile [74]. Use of the $99^{\text {th }}$ percentile independent of the coefficient of variation has a very low false positive rate for diagnosing acute myocardial infarction and has recently been validated [77]. Thus, $0.01 \mu \mathrm{g} / \mathrm{L}$ will be the cutoff for a diagnosis of acute myocardial infarction. These reference values conform to the ESC/ACC guidelines for use of existing assays clinically and for clinical trials $[2,70]$.

Having at least a 6 hour interval between cTNT specimens is the AHA definition of an adequate set of biomarkers $[2,78]$. However, recent data suggest that specimens drawn at least 3 hours apart have the same rate of detection of acute myocardial infarction as the AHA schedule, as long as at least one specimen is drawn $\geq 6$ hours after pain onset [79]. Thus, CTNT will be measured at emergency department arrival and $\geq 6$ hours from pain onset, with at least 3 hours between samples [79].

\section{Run-in period}

The data collection forms, patient assessment techniques, and patient follow-up questions will be evaluated during an 8-week run-in period prior to the actual study. This will allow time for training of the physician assessors and revision of the data collection forms as appropriate.

\section{Interobserver reliability}

A subset of patients will be assessed by a second emergency physician who will be blinded to the results of the first assessment. These second assessments will be performed on a feasibility basis whenever two study physicians are available.

\section{Outcome measures}

The primary outcome will be acute myocardial infarction, death of cardiac or unknown cause, or revascularization within 30 days of the emergency department visit. The secondary outcome will be acute myocardial infarction, 
death of cardiac or unknown cause, revascularization, or a new perfusion defect demonstrated on myocardial perfusion imaging.

Acute myocardial infarction will be defined as any one of the following: (1) a cardiac troponin $\mathrm{T}(\mathrm{cTnT}) \geq 0.01$ with a rising or falling pattern (defined as a change of $\geq 0.03$ $\mathrm{ng} / \mathrm{mL}$ for values that are initially $<0.2 \mathrm{ng} / \mathrm{mL}$; for levels $\geq$ $0.20 \mathrm{ng} / \mathrm{mL}$, a positive cTnT will be defined as a change of $\geq 20 \%$ between samples) $[1,72,80]$ or (2) development of pathological Q-waves on the ECG or ECG evolution consistent with acute myocardial infarction. Revascularization will be defined as reestablishment of coronary artery patency by percutaneous coronary angioplasty with or without stent placement or coronary artery bypass graft (CABG) surgery. The final component of the primary outcome will be death of cardiac or unknown cause within 30 days of the emergency department visit.

The primary outcome will be determined by investigators blinded to the knowledge of the predictor variables. If a diagnosis cannot be assigned, 2 coinvestigators will review all clinical data and assign an adjudicated outcome diagnosis. If a consensus can not be reached between two co-investigators, an adjudicated diagnosis will be assigned by the primary investigator. If all 3 disagree, the final diagnosis will be the most significant diagnosis. The reliability of the primary outcome determination will be assessed by having all positive outcomes and 10\% (randomly selected) of patients with negative outcomes reviewed by an investigator blinded to the first interpretation.

\section{Data analysis}

Interobserver agreement for each variable will be measured by calculating the kappa coefficient, the proportion of potential agreement beyond chance, along with 95\% confidence intervals. Variables with kappa values $\geq 0.6$ will be considered to represent "substantial agreement" and considered for inclusion in the clinical rule.

\section{Univariate analysis}

Univariate analysis will be used to determine the strength of association between each variable and the primary outcome. The appropriate univariate technique will be chosen for the type of data: for nominal data, the chi-square test with continuity correction; for ordinal variables, the Mann-Whitney U test; and, for continuous variables, the unpaired 2-tailed t-test, using pooled or separate variance estimates as appropriate.

\section{Multivariable analysis}

Multivariable analysis will be used to derive a model to predict the primary outcome. Variables found to be both reliable (kappa $\geq 0.6$ ) and strongly associated with the primary outcome $(\mathrm{p}<0.05)$ will be evaluated with both logistic regression and recursive partitioning. Second order interaction among predictor variables that are known to be clinically related will be evaluated using Mantel-Haenszel and logistic model procedures. Appropriate composite variables will be considered for incorporation in the multivariate analyses. The objective will be to find the best combination of predictor variables that are highly sensitive for detecting the primary outcome while achieving the maximum possible specificity. To be clinically acceptable, the model must be nearly $100 \%$ sensitive and contain the fewest number of predictor variables to facilitate ease of use by clinicians.

Recursive partitioning will be performed using KnowledgeSEEKER Version 5.2 software (Angoss Software International, Toronto) [81-83]. In recursive partitioning, the relationship between a dependent outcome variable $(\mathrm{Y})$ and a series of predictor variables $(\mathrm{X})$ is defined by a series of binary splits, resulting in a decision tree in which data are partitioned into several nodes or leaves along branches. The significance of each binary split can be quantified based on the chi-square technique.

Attempts to find the best model will also be made by performing logistic regression as an alternative technique. Model building will proceed with forward stepwise selection until no variables meet the entry $(0.05)$ or removal $(0.10)$ criteria for the significance level of the likelihood ratio test. In order to provide a simpler model for clinicians, cutpoints will be sought for continuous variables. The variables chosen by the best model will constitute the decision rule.

\section{Classification performance}

The derived decision rule will be evaluated by comparing the classification of each patient to their actual status for the primary outcome. This will enable an estimate of the sensitivity and specificity of the rule, with $95 \%$ confidence intervals.

\section{Patient subgroups}

The classification performance of the decision rule will be assessed in the following patient subgroups: a) patients with and without a prior cardiac history b) patients with ECG's classified as normal or nonspecific ST-T wave changes and negative cardiac biomarkers and c) patients with outcomes at $0,4,14$, and 30 days from the emergency department visit.

\section{Physician judgment}

Data from questions relating to physicians' predictions will be tabulated and presented in descriptive format. The probability will be used to calculate a receiving operating characteristic (ROC) curve for the diagnosis of acute coronary syndrome. 


\section{Sample size}

Excluding the run-in stage, 1200 patients will be enrolled over 12 months at the study hospitals during phase I. Since no hypothesis is being tested, the sample size is based on estimation of the precision of the sensitivity of the derived decision rule as well as on the precision of the estimates of interobserver variability and the logistic regression coefficients. The sample size has to accommodate a large number of clinical variables (31), a large number of physicians (more than 60), the prevalence of acute coronary syndrome (21\% of eligible patients in two recent Canadian studies $[7,19])$, as well as our plans to assess subgroups. A sample size of 1200 patients with possible ACS in which $11 \%$ of cases are excluded for ST segment elevation should yield approximately 120 ACS cases. 120 cases are needed to derive a rule that is $100 \%$ sensitive with upper and lower 95\% confidence limits of $100 \%$ and $97.0 \%$, respectively.

\section{Ethics approval}

Research ethics board approval was obtained from The Ottawa Hospital. As the study will not affect usual practice, there were no specific ethical concerns. At enrolment, participants will be informed that they will be contacted by phone in one month to determine their status, and verbal consent will be obtained at the time of the follow-up phone call. Personal identifiers will be removed from clinical records where present and not stored in the study database.

\section{Discussion}

Chest pain is a diagnostic dilemma for the emergency physician. In the absence of an accurate and reliable method of identifying patients at very low risk for adverse cardiac events, physicians' triage decisions are variable and often influenced by level of perceived medical and legal risk [15]. As a result very low risk patients are triaged to chest pain observation units and undergo extensive risk stratification protocols based on an unstructured assessment of pretest probability and perceived legal risk [16]. Despite this inefficiency, a number of emergency department patients at risk for adverse cardiac events are being missed [8].

We aim to derive a clinical decision rule that is highly sensitive for predicting acute myocardial infarction, need for revascularization, or death within 30 days of presentation to the emergency department using techniques successfully applied to ankle, knee, and cervical spine radiography [84-86]. Future plans are to prospectively validate the derived rule in new set of patients. This will improve patient care, lower healthcare costs, and improve flow in our busy and overcrowded emergency departments.

\section{Competing interests}

The author(s) declare that they have no competing interests.

\section{Authors' contributions}

EH conceived of the study and drafted the manuscript. GW assisted with the statistical design and methodology. AJ assisted with the methodology and revised it critically for important intellectual content. IS assisted with the methodology, revised it critically for important intellectual content, and helped to draft the manuscript. All authors read and approved the final manuscript.

\section{Acknowledgements}

This study is jointly funded by the American Heart Association, the Society for Academic Emergency Medicine, and the Emergency Medicine Foundation.

\section{References}

I. Thygesen K, Alpert JS, White HD: Joint ESC/ACCF/AHA/WHF Task Force for the Redefinition of Myocardial Infarction. Universal definition of myocardial infarction. Circulation 2007, I 16:1-20.

2. Luepker RV, Apple FS, Christenson RH, Crow RS, Fortmann SP, Goff D, Goldberg RJ, Hand MM, Jaffe AS, Julian DG, et al.: Case definitions for acute coronary heart disease in epidemiology and clinical research studies: a statement from the AHA Council on Epidemiology and Prevention; AHA Statistics Committee; World Heart Federation Council on Epidemiology and Prevention; the European Society of Cardiology Working Group on Epidemiology and Prevention; Centers for Disease Control and Prevention; and the National Heart, Lung, and Blood Institute. Circulation 2003, I08(20):2543-2549.

3. McCaig LF, Burt CW: National Hospital Ambulatory Medical Care Survey: 2004 emergency department summary. Adv Data 2006:I-32.

4. Rosamond W, Flegal K, Friday G, Furie K, Go A, Greenlund K, Haase N, Ho M, Howard V, Kissela B, et al.: Heart disease and stroke statistics--2007 update: a report from the American Heart Association Statistics Committee and Stroke Statistics Subcommittee. Circulation 2007, I I 5(5):e69- I 7 I. Epub 2006 Dec 2028

5. Kontos MC, Jesse RL: Evaluation of the emergency department chest pain patient. American Journal of Cardiology 2000:32B-39B.

6. Pope JH, Ruthazer R, Beshansky JR, Griffith JL, Selker HP: The clinical presentation of patients with acute cardiac ischemia in the emergency department: a multicenter controlled clinical trial. Journal of Thrombosis and Thrombolysis 1998:63-74.

7. Christenson J, Innes G, McKnight D, Boychuk B, Grafstein E, Thompson CR, Rosenberg F, Anis A, Gin K, Tilley J, et al.: Safety and efficiency of emergency department assessment of chest discomfort. CMAJ Canadian Medical Association Journal 2004: 1803-1807.

8. Pope $J \mathrm{H}$, Aufderheide TP, Ruthazer R, Woolard RH, Feldman JA, Beshansky JR, Griffith JL, Selker HP: Missed diagnoses of acute cardiac ischemia in the emergency department. New England Journal of Medicine 2000, 342(16): I I63-1 I 70.

9. Swap CJ, Nagurney JT: Value and limitations of chest pain history in the evaluation of patients with suspected acute coronary syndromes. JAMA 2005, 294(20):2623-2629.

10. Limkakeng A Jr, Gibler WB, Pollack C, Hoekstra JW, Sites F, Shofer FS, Tiffany B, Wilke E, Hollander JE: Combination of Goldman risk and initial cardiac troponin I for emergency department chest pain patient risk stratification [see comment]. Academic Emergency Medicine 200I, 8(7):696-702.

II. Anderson JL, Adams CD, Antman EM, Bridges CR, Califf RM, Casey DE Jr, Chavey WE 2nd, Fesmire FM, Hochman JS, Levin TN, et al: ACC/AHA 2007 guidelines for the management of patients with unstable angina/non ST-elevation myocardial infarction: a report of the American College of Cardiology/American Heart Association Task Force on Practice Guidelines 
(Writing Committee to Revise the $\mathbf{2 0 0 2}$ Guidelines for the Management of Patients With Unstable Angina/Non ST-Elevation Myocardial Infarction): developed in collaboration with the American College of Emergency Physicians, the Society for Cardiovascular Angiography and Interventions, and the Society of Thoracic Surgeons: endorsed by the American Association of Cardiovascular and Pulmonary Rehabilitation and the Society for Academic Emergency Medicine. Circulation 2007, I I 6(7):e I 48-304. Epub 2007

12. Gibler WB, Cannon CP, Blomkalns AL, Char DM, Drew BJ, Hollander JE, Jaffe AS, Jesse RL, Newby LK, Ohman EM, et al.: Practical Implementation of the Guidelines for Unstable Angina/Non-ST. Segment Elevation Myocardial Infarction in the Emergency Department: A Scientific Statement From the American Heart Association Council on Clinical Cardiology (Subcommittee on Acute Cardiac Care), Council on Cardiovascular Nursing, and Quality of Care and Outcomes Research Interdisciplinary Working Group, in Collaboration With the Society of Chest Pain Centers. Circulation 2005, I I I(20):2699-27IO.

13. Katz DA, Williams GC, Brown RL, Aufderheide TP, Bogner M, Rahko PS, Selker HP: Emergency physicians' fear of malpractice in evaluating patients with possible acute cardiac ischemia. Annals of Emergency Medicine 2005, 46(6):525-533.

14. Ting HH, Lee TH, Soukup JR, Cook EF, Tosteson AN, Brand DA Rouan GW, Goldman L: Impact of physician experience on triage of emergency room patients with acute chest pain at three teaching hospitals. American Journal of Medicine 1991, 9 I (4):40I-408.

15. Pearson SD, Goldman L, Orav EJ, Guadagnoli E, Garcia TB, Johnson PA, Lee TH: Triage decisions for emergency department patients with chest pain: do physicians' risk attitudes make the difference? Journal of General Internal Medicine 1995 I0(10):557-564.

16. Zalenski RJ, Rydman RJ, Ting S, Kampe L, Selker HP: A national survey of emergency department chest pain centers in the United States. American Journal of Cardiology 1998, 8I(II): I305-1309.

17. Stiell IG, Wells GA: Methodologic standards for the development of clinical decision rules in emergency medicine. Annals of Emergency Medicine 1999, 33(4):437-447.

18. Laupacis A, Sekar N, Stiell IG: Clinical prediction rules. A review and suggested modifications of methodological standards. JAMA 1997, 277(6):488-494.

19. Christenson J, Innes G, McKnight D, Thompson CR, Wong H, Yu E, Boychuk B, Grafstein E, Rosenberg F, Gin K, et al: A clinical prediction rule for early discharge of patients with chest pain. Annals of Emergency Medicine 2006, 47(I): I-10.

20. Baxt WG: Use of an artificial neural network for data analysis in clinical decision-making: the diagnosis of acute coronary occlusion. Neural Computation 1991, 2:480-489.

21. Baxt WG: Use of an artificial neural network for the diagnosis of myocardial infarction. Annals of Internal Medicine 1991, I I 5(I I):843-848

22. Baxt WG, Skora J: Prospective validation of artificial neural network trained to identify acute myocardial infarction. Lancet 1996, 347(8993): $12-15$

23. Baxt WG, Shofer FS, Sites FD, Hollander JE: A neural network aid for the early diagnosis of cardiac ischemia in patients presenting to the emergency department with chest pain. Annals of Emergency Medicine 2002, 40(6):575-583.

24. Baxt WG, Shofer FS, Sites FD, Hollander JE: A neural computational aid to the diagnosis of acute myocardial infarction. Annals of Emergency Medicine 2002, 39(4):366-373.

25. Goldman L, Weinberg M, Weisberg M, Olshen R, Cook EF, Sargent RK, Lamas GA, Dennis C, Wilson C, Deckelbaum L, et al.: A computer-derived protocol to aid in the diagnosis of emergency room patients with acute chest pain. New England Journal of Medicine 1982, 307(10):588-596.

26. Goldman L, Cook EF, Brand DA, Lee TH, Rouan GW, Weisberg MC, Acampora D, Stasiulewicz C, Walshon J, Terranova G, et al.: A computer protocol to predict myocardial infarction in emergency department patients with chest pain. New England Journal of Medicine 1988, 31 8( I 3):797-803.

27. Kennedy RL, Burton AM, Fraser HS, McStay LN, Harrison RF: Early diagnosis of acute myocardial infarction using clinical and electrocardiographic data at presentation: Derivation and evaluation of logistic regression models. European Heart Journal 1996, I7(8):||18|-||9|.

28. Mair J, Smidt J, Lechleitner P, Dienstl F, Puschendorf B: A decision tree for the early diagnosis of acute myocardial infarction in nontraumatic chest pain patients at hospital admission. Chest 1995, 108(6): 1502-1509.

29. Mair J, Smidt J, Lechleitner P, Dienstl F, Puschendorf B: Rapid accurate diagnosis of acute myocardial infarction in patients with non-traumatic chest pain within I h of admission. Coronary Artery Disease 1995, 6(7):539-545.

30. Ng SM, Krishnaswamy P, Morissey R, Clopton P, Fitzgerald R, Maisel AS: Ninety-minute accelerated critical pathway for chest pain evaluation. American Journal of Cardiology 200I, 88(6):6||-6|7.

31. Poretsky L, Leibowitz IH, Friedman SA: The diagnosis of myocardial infarction by computer-derived protocol in a municipal hospital. Angiology 1985, 36(3): 165-170.

32. Tierney WM, Roth BJ, Psaty B, McHenry R, Fitzgerald J, Stump DL, Anderson FK, Ryder KW, McDonald CJ, Smith DM: Predictors of myocardial infarction in emergency room patients. Critical Care Medicine 1985, I3(7):526-531.

33. Bassan R, Pimenta L, Scofano M, Soares JF: Accuracy of a neural diagnostic tree for the identification of acute coronary syndrome in patients with chest pain and no ST-segment elevation. Critical Pathways in Cardiology: A Journal of Evidence-Based Medicine 2004, 3(2):72-78.

34. Harrison RF, Kennedy RL: Artificial neural network models for prediction of acute coronary syndromes using clinical data from the time of presentation. Annals of Emergency Medicine 2005, 46(5):43I-439.

35. Bjork J, Forberg JL, Ohlsson M, Edenbrandt L, Ohlin H, Ekelund U: A simple statistical model for prediction of acute coronary syndrome in chest pain patients in the emergency department. BMC Medical Informatics \& Decision Making 2006, 6:28.

36. Selker HP, Beshansky JR, Griffith JL, Aufderheide TP, Ballin DS, Bernard SA, Crespo SG, Feldman JA, Fish SS, Gibler WB, et al.: Use of the acute cardiac ischemia time-insensitive predictive instrument (ACl-TIPI) to assist with triage of patients with chest pain or other symptoms suggestive of acute cardiac ischemia. A multicenter, controlled clinical trial. Annals of Internal Medicine 1998, I 29(I I ):845-855

37. Chandra A, Jones FM, Beam D, Promes SB, Kline JA, Cairns CB: Limited Utility of the Acute Cardiac Ischemia Time-Insensitive Predictive Instrument (ACI-TIPI) in the Evaluation of Chest Pain Unit Patients. Acad Emerg Med 2005, I 2(Suppl I): 30-b-3I

38. Eagle KA, Lim MJ, Dabbous OH, Pieper KS, Goldberg RJ, Van de Werf F, Goodman SG, Granger CB, Steg PG, Gore JM, et al.: A validated prediction model for all forms of acute coronary syndrome: estimating the risk of 6-month postdischarge death in an international registry. JAMA 2004, 29 I(22):2727-2733.

39. Fox KA, Dabbous OH, Goldberg RJ, Pieper KS, Eagle KA, Van de Werf F, Avezum A, Goodman SG, Flather MD, Anderson FA Jr, et al:: Prediction of risk of death and myocardial infarction in the six months after presentation with acute coronary syndrome: prospective multinational observational study (GRACE). BM] 2006, 333(7578): 1091. Epub 2006

40. de Araujo Goncalves P, Ferreira J, Aguiar C, Seabra-Gomes R: TIMI, PURSUIT, and GRACE risk scores: sustained prognostic value and interaction with revascularization in NSTE-ACS. Eur Heart J 2005, 26(9):865-872. Epub 2005

4I. Antman EM, Cohen M, Bernink PJ, McCabe CH, Horacek T, Papuchis G, Mautner B, Corbalan R, Radley D, Braunwald E: The TIMI risk score for unstable angina/non-ST elevation MI: A method for prognostication and therapeutic decision making. JAMA 2000, 284(7):835-842.

42. Chase M, Robey JL, Zogby KE, Sease KL, Shofer FS, Hollander JE: Prospective validation of the Thrombolysis in Myocardial Infarction Risk Score in the emergency department chest pain population. Annals of Emergency Medicine 2006, 48(3):252-259.

43. Conway Morris A, Caesar D, Gray S, Gray A: TIMI risk score accurately risk stratifies patients with undifferentiated chest pain presenting to an emergency department. Heart 2006, 92(9): 1333-1334

44. Garcia Almagro FJ, Gimeno JR, Villegas M, Munoz L, Sanchez E, Teruel F, Hurtado J, Gonzalez J, Antolinos MJ, Pascual D, et al:: Use of a coronary risk score (the TIMI Risk Score) in a non-selected 
patient population assessed for chest pain at an emergency department. Revista Espanola de Cardiologia 2005, 58(7):775-78I.

45. Jaffery Z, Hudson MP, Jacobsen G, Nowak R, McCord J: Modified Thrombolysis in Myocardial Infarction (TIMI) risk score to risk stratify patients in the emergency department with possible acute coronary syndrome. J Thromb Thrombolysis 2007, 24(2): I37-I44. Epub 2007

46. Lyon R, Morris AC, Caesar D, Gray S, Gray A: Chest pain presenting to the Emergency Department-to stratify risk with GRACE or TIMI? Resuscitation 2007, 74(I):90-93.

47. Pollack CV Jr, Sites FD, Shofer FS, Sease KL, Hollander JE: Application of the TIMI risk score for unstable angina and non-ST elevation acute coronary syndrome to an unselected emergency department chest pain population. Academic Emergency Medicine 2006, 13(I):13-18

48. Boersma E, Pieper KS, Steyerberg EW, Wilcox RG, Chang WC, Lee KL, Akkerhuis KM, Harrington RA, Deckers JW, Armstrong PW, et al.: Predictors of outcome in patients with acute coronary syndromes without persistent ST-segment elevation. Results from an international trial of 946 I patients. The PURSUIT Investigators. Circulation 2000, I0I(22):2557-2567.

49. Domanovits $H$, Schillinger $M$, Paulis M, Rauscha $F$, Thoennissen J, Nikfardjam M, Laggner AN: Acute chest pain-a stepwise approach, the challenge of the correct clinical diagnosis. Resuscitation 2002, 55(I):9-16.

50. Mitchell AM, Garvey JL, Chandra A, Diercks D, Pollack CV, Kline JA: Prospective multicenter study of quantitative pretest probability assessment to exclude acute coronary syndrome for patients evaluated in emergency department chest pain units. Annals of Emergency Medicine 2006, 47(5):447.

5I. Tong KL, Kaul S, Wang XQ, Rinkevich D, Kalvaitis S, Belcik T, Lepper W, Foster WA, Wei K: Myocardial contrast echocardiography versus Thrombolysis In Myocardial Infarction score in patients presenting to the emergency department with chest pain and a nondiagnostic electrocardiogram. Journal of the American College of Cardiology 2005, 46(5):920-927.

52. Fernandez Portales J, Perez Reyes F, Garcia Robles JA, Jimenez Candil J, Perez David E, Rey Blas JR, Perez de Isla L, Diaz Castro O, Almendral J: Risk stratification using combined ECG, clinical, and biochemical assessment in patients with chest pain without ST-segment elevation. How long should we wait? Revista Espanola de Cardiologia 2003, 56(4):338-345.

53. Goldman L, Cook EF, Johnson PA, Brand DA, Rouan GW, Lee TH: Prediction of the need for intensive care in patients who come to the emergency departments with acute chest pain New England Journal of Medicine 1996, 334(23): I498-I504.

54. Reilly B, Durairaj L, Husain S, Acob C, Evans A, Hu TC, Das K, McNutt R: Performance and potential impact of a chest pain prediction rule in a large public hospital. American Journal of Medicine 1999, 106(3):285-291.

55. Durairaj L, Reilly B, Das K, Smith C, Acob C, Husain S, Saquib M, Ganschow P, Evans A, McNutt R: Emergency department admissions to inpatient cardiac telemetry beds: a prospective cohort study of risk stratification and outcomes. Am J Med 200I, I IO(I):7-II

56. Reilly BM, Evans AT, Schaider IJ, Das K, Calvin JE, Moran LA, Roberts $\mathrm{RR}$, Martinez E: Impact of a clinical decision rule on hospital triage of patients with suspected acute cardiac ischemia in the emergency department. JAMA 2002, 288(3):342-350.

57. Marsan RJ Jr, Shaver KJ, Sease KL, Shofer FS, Sites FD, Hollander JE: Evaluation of a clinical decision rule for young adult patients with chest pain. Academic Emergency Medicine 2005, I 2(I):26-3I.

58. Martinez-Selles M, Ortiz J, Estevez A, Andueza J, de Miguel J, Bueno $H$ : A new risk score for patients with a normal or non-diagnostic ECG admitted to a chest pain unit. Revista Espanola de Cardiologia 2005, 58(7):782-788.

59. Lorenzoni R, Ebert AG, Lattanzi F, Orsini E, Mazzoni A, Magnani M Barbieri C, Rossi M, Mazzuoli F: A computer protocol to evaluate subjects with chest pain in the emergency department: a multicenter study. Journal of Cardiovascular Medicine 2006 , 7(3):203-209.

60. Porela P, Pulkki K, Helenius H, Antila KJ, Pettersson K, Wacker M, Voipio-Pulkki LM: Prediction of short-term outcome in patients with suspected myocardial infarction. Annals of Emergency Medicine 2000, 35(5):413-420.
6I. Selker HP, Griffith JL, D'Agostino RB: A time-insensitive predictive instrument for acute myocardial infarction mortality: a multicenter study. Medical Care 1991, 29(12): I196-12II.

62. Seyal JM, Clark EN, Macfarlane PW: Diagnosis of acute myocardial ischaemia using probabilistic methods. Journal of Cardiovascular Risk 2002, 9(2): II5-I21.

63. Miller CD, Lindsell CJ, Anantharaman V, Greenway J, Pollack CV, Tiffany BR, Hollander JE, Gibler WB, Hoekstra JW: Performance of a population-based cardiac risk stratification tool in Asian patients with chest pain. Academic Emergency Medicine 2005, I 2(5):423-430

64. Walker NJ, Sites FD, Shofer FS, Hollander JE: Characteristics and outcomes of young adults who present to the emergency department with chest pain. Academic Emergency Medicine 200I, 8(7):703-708.

65. Diercks DB, Hollander JE, Sites F, Kirk JD: Derivation and validation of a risk stratification model to identify coronary artery disease in women who present to the emergency department with potential acute coronary syndromes. Academic Emergency Medicine 2004, I I (6):630-634.

66. Macgougan CK, Christenson JM, Innes GD, Raboud J: Emergency physicians' attitudes toward a clinical prediction rule for the identification and early discharge of low risk patients with chest discomfort. CJEM 200I, 3(2):89-94.

67. Forest RS, Shofer FS, Sease KL, Hollander JE: Assessment of the standardized reporting guidelines ECG classification system: the presenting ECG predicts 30-day outcomes. Ann Emerg Med 2004:206-I2.

68. Weber JE, Shofer FS, Larkin GL, Kalaria AS, Hollander JE: Validation of a brief observation period for patients with cocaine-associated chest pain[see comment]. New England Journal of Medicine 2003, 348(6):510-517.

69. Collinson PO, Gaze DC, Morris F, Morris B, Price A, Goodacre S: Comparison of biomarker strategies for rapid rule out of myocardial infarction in the emergency department using ACC/ESC diagnostic criteria. Annals of Clinical Biochemistry 2006, 43(4):273-280

70. Apple FS, Wu AH, Jaffe AS: European Society of Cardiology and American College of Cardiology guidelines for redefinition of myocardial infarction: how to use existing assays clinically and for clinical trials[see comment]. American Heart Journal 2002, I 44(6):98I-986

7I. Panteghini M, Pagani F, Yeo KT, Apple FS, Christenson RH, Dati F, Mair J, Ravkilde J, Wu AH, Committee on Standardization of Markers of Cardiac Damage of the l: Evaluation of imprecision for cardiac troponin assays at low-range concentrations. Clinical Chemistry 2004, 50(2):327-332.

72. Wallace TW, Abdullah SM, Drazner MH, Das SR, Khera A, McGuire DK, Wians F, Sabatine MS, Morrow DA, de Lemos JA: Prevalence and determinants of troponin T elevation in the general population. Circulation 2006, I I 3(16): 1958-1965.

73. Aviles RJ, Askari AT, Lindahl B, Wallentin L, Jia G, Ohman EM, Mahaffey KW, Newby LK, Califf RM, Simoons ML, et al.: Troponin T levels in patients with acute coronary syndromes, with or without renal dysfunction[see comment][summary for patients in CMAJ. 167(6):67 I;PMID: | 2358205]. New England Journal of Medicine 346(26):2047-2052. 2002 Sep 17; 2002

74. Hamm CW, Goldmann BU, Heeschen C, Kreymann G, Berger J, Meinertz $\mathrm{T}$ : Emergency room triage of patients with acute chest pain by means of rapid testing for cardiac troponin $T$ or troponin I[see comment]. New England Journal of Medicine 1997, 337(23): 1648-1653.

75. Kavsak PA, MacRae AR, Lustig V, Bhargava R, Vandersluis R, Palomaki GE, Yerna MJ, Jaffe AS: The impact of the ESCIACC redefinition of myocardial infarction and new sensitive troponin assays on the frequency of acute myocardial infarction. American Heart Journal 2006, 152(I): I18-125.

76. Jaffe AS: Chasing troponin: how low can you go if you can see the rise? J Am Coll Cardiol 2006, 48(9): 1763-1764.

77. Apple FS, Parvin CA, Buechler KF, Christenson RH, Wu AH, Jaffe AS Validation of the 99th percentile cutoff independent of assay imprecision (CV) for cardiac troponin monitoring for ruling out myocardial infarction. Clinical Chemistry 2005, 5 I (II):2198-2200.

78. Gibler WB, Cannon CP, Blomkalns AL, Char DM, Drew BJ, Hollander JE, Jaffe AS, Jesse RL, Newby LK, Ohman EM, et al:: Practical imple- 
mentation of the guidelines for unstable angina/non-ST-segment elevation myocardial infarction in the emergency department: a scientific statement from the American Heart Association Council on Clinical Cardiology (Subcommittee on Acute Cardiac Care), Council on Cardiovascular Nursing, and Quality of Care and Outcomes Research Interdisciplinary Working Group, in Collaboration With the Society of Chest Pain Centers. Circulation 2005, I I I (20):2699-27I0.

79. Macrae AR, Kavsak PA, Lustig V, Bhargava R, Vandersluis R, Palomaki GE, Yerna MJ, Jaffe AS: Assessing the requirement for the 6hour interval between specimens in the American Heart Association Classification of Myocardial Infarction in Epidemiology and Clinical Research Studies[see comment]. Clinical Chemistry 2006, 52(5):8I2-8I8.

80. Macrae AR, Kavsak PA, Lustig V, Bhargava R, Vandersluis R, Palomaki GE, Yerna MJ, Jaffe AS: Assessing the requirement for the 6hour interval between specimens in the American Heart Association Classification of Myocardial Infarction in Epidemiology and Clinical Research Studies. Clinical Chemistry 2006, 52(5):8|2-8|8.

81. Friedman $\mathrm{JH}:$ A recursive partitioning decision rule for nonparametric classification. IEETransComput 1977, 16:404-408.

82. Ciampi A, Hogg SA, McKinney S, Thiffault J: RECPAM: a computer program for recursive partition and amalgamation for censored suvival data and other situations frequently occurring in biostatistics. I. Methods and program features. Comput Methods Programs Biomed 1988, 26:239-256.

83. Ciampi A, Thiffault J, Nakache JP, Asselain B: Stratification by stepwise regression, correspondence analysis and recursive partition: a comparison of three methods of analysis for survival data with covariates. ComputStatDataAnal 1986, 4: I85-204.

84. Stiell IG, McKnight RD, Greenberg GH, McDowell I, Nair RC, Wells GA, Johns C, Worthington JR: Implementation of the Ottawa ankle rules. JAMA I994, 27I(I I):827-832.

85. Stiell IG, Wells GA, Hoag RH, Sivilotti ML, Cacciotti TF, Verbeek PR, Greenway KT, McDowell I, Cwinn AA, Greenberg GH, et al.: Implementation of the Ottawa Knee Rule for the use of radiography in acute knee injuries. JAMA 1997, 278(23):2075-2079.

86. Stiell IG, Wells GA, Vandemheen KL, Clement CM, Lesiuk H, De Maio VJ, Laupacis A, Schull M, McKnight RD, Verbeek R, et al.: The Canadian C-spine rule for radiography in alert and stable trauma patients. JAMA 200I, 286(15):I84I-I848.

\section{Pre-publication history}

The pre-publication history for this paper can be accessed here:

http://www.biomedcentral.com/1471-227X/8/3/prepub
Publish with Bio Med Central and every scientist can read your work free of charge

"BioMed Central will be the most significant development for disseminating the results of biomedical research in our lifetime. "

Sir Paul Nurse, Cancer Research UK

Your research papers will be:

- available free of charge to the entire biomedical community

- peer reviewed and published immediately upon acceptance

- cited in PubMed and archived on PubMed Central

- yours - you keep the copyright
BioMedcentral 